\title{
The importance of cuticular permeance in assessing plant water use strategies
}

\author{
Matthew Lanning ${ }^{1}$, Lixin Wang ${ }^{1 *}$ and Kimberly A. Novick ${ }^{2}$
}

${ }^{1}$ Department of Earth Science, Indiana University-Purdue University Indianapolis, 723 West Michigan Street, Indianapolis, IN 46202, USA

${ }^{2}$ School of Public and Environmental Affairs, Indiana University Bloomington, 1315 East Tenth Street, Bloomington, IN 47405, USA

* Correspondence to:

Lixin Wang (lxwang@iupui.edu)

Department of Earth Sciences

Indiana University-Purdue University Indianapolis

Indianapolis, IN 46202, USA

Office phone number: 317-274-7764

\begin{abstract}
Accurate understanding of plant responses to water stress is increasingly important for quantification of ecosystem carbon and water cycling under future climates. Plant water use strategies can be characterized across a spectrum of water stress responses, from tight stomatal control (isohydric) to distinctly less stomatal control (anisohydric). A recent and popular classification method of plant water use strategies utilizes the regression slope of predawn and midday leaf water potentials, $\sigma$, to reflect the coupling of soil water availability (predawn leaf water potential) and stomatal dynamics (daily decline in leaf water potential). This type of classification is important in predicting ecosystem drought response and resiliency. However, it fails to explain the relative stomatal responses to drought of Acer sacharrum and Quercus alba, improperly ranking them on the spectrum of isohydricity. We argue this inconsistency may be in part due to the cuticular conductance of different species. We used empirical and modeling evidence to show that plants with more permeable cuticles are more often classified as anisohydric; the $\sigma$ values of those species were very well correlated with measured cuticular permeance. Furthermore, we found that midday leaf water potential in species with more permeable cuticles would continue to decrease as soils become drier, but not in those with less permeable cuticles. We devised a diagnostic parameter, $\Gamma$, to identify circumstances where the impact of cuticular conductance could cause species misclassification. The results suggest that cuticular conductance needs to be considered to better understand plant water use strategies and to accurately predict forest responses to water stress under future climate scenarios.
\end{abstract}

\section{Keywords}

cuticle, ecohydrology, drought, isohydricity, stomata, water stress

This is the author's manuscript of the article published in final edited form as: 


\section{Introduction}

Vegetation is a dominant factor controlling the hydrological cycle (Jasechko et al., 2013; Lanning et al., 2019; Schlesinger \& Jasechko, 2014; Wang, Good, \& Caylor, 2014). Diverse vegetation responses to water stress have important consequences in ecosystem carbon and water cycles. Plants respond to water stress in a multitude of ways. At the leaf level, some plants tightly control their stomata in response to drought (isohydric), others don't (anisohydric), and a spectrum of incrementally different responses exist between these two end members (Klein, 2014; Oren et al., 1999; Tardieu, Lafarge, \& Simonneau, 1996). A quantitative definition of plant water use strategies which compliments empirical observations has been highly sought after within the plant physiology, ecosystem ecology, and ecohydrology communities. Of these attempts, one of the more popular ways to rank water use strategies is that proposed by MartinezVilalta et al. 2014 which leveraged existing measurements of predawn leaf water potential $\left(\Psi_{\mathrm{PD}}\right)$ and midday leaf water potential $\left(\Psi_{\mathrm{MD}}\right)$ to define a quantitative representation of isohydricity (Martinez-Vilalta et al., 2014). The slope $(\sigma)$ of a regression between $\Psi_{\mathrm{PD}}$ and $\Psi_{\mathrm{MD}}\left(\right.$ e.g., $\left.\sigma=\partial \Psi_{M D} / \partial \Psi_{P D}\right)$ defines the position of a particular species along the isohydric continuum. By definition, $\sigma$ has mathematical meaning in describing the response of stomata to increased soil water deficit (Martinez-Vilalta et al. 2014, see proof and references within), id est, the larger the absolute value of $\sigma$, the more anisohydric the species is.

This definition of isohydricity, while useful and easy to apply, has recently come under criticism for its failure to fully capture links between leaf water potential and stomatal functioning across spatial and temporal gradients (Hochberg, Rockwell, Holbrook, \& Cochard, 2018; Martínez-Vilalta \& Garcia-Forner, 2017). For example, this definition cannot satisfactorily explain the relative stomatal dynamics of two eastern United States tree species groups known to possess different drought response strategies: Acer species (specifically, Acer sacharrum and Acer rubrum) and Quercus species (specifically, Quercus alba and Quercus rubra). Loewenstein and Pallardy (1998) report that both maples and oaks are anisohydric species, which is consistent with $\sigma$ based classification. However, subsequent empirical work suggests that oaks are substantially more anisohydric than maples (Kannenberg, Novick, \& Phillips, 2019; Roman et al., 2015; Thomsen et al., 2013; Yi, Dragoni, Phillips, Roman, \& Novick, 2017). The Acer species mentioned earlier have been observed to maintain a more consistent leaf water potential ( $\Psi_{\text {leaf }}$ ) by reducing stomatal conductance under drought conditions, whereas the Quercus species do not do this (Roman et al., 2015). Instead, Quercus maintains sap flux and stomatal conductance values similar to non-drought conditions (Roman et al., 2015; Yi et al., 2017), likely supplemented by deeper water sources as has been observed in other studies (Matheny et al., 2016; Thomsen et al., 2013). However, rooting depth alone cannot explain the decoupling between $\sigma$ and stomatal dynamics, as deeper roots should promote more stationarity in both $\Psi_{\text {leaf }}$ and conductance, whereas the evidence suggests that high conductance is sustained despite substantial variability in mid-day oak $\Psi_{\text {leaf. }}$ In other words, leaf water potential based classification methods contradict observed stomatal behavior in oaks and maples.

A reason for this paradox may be failing to consider cuticular permeance, sometimes expressed as cuticular conductance, which has been described as a parameter that needs consideration by MartínezVilalta \& Garcia-Forner, 2017, a paper critical of Martinez-Vilalta et al. 2014. We propose that cuticular permeance influences plant water use strategies and that cuticular permeance variation (and minimum conductance generally) provides a mechanistic explanation of how $\sigma$ can be a successful indicator of isohydricity in one location but fail in others. 


\section{The consequence of cuticular water loss - a modeling perspective}

Water loss via the leaf is primarily but not exclusively through stomatal pore, as the cuticle of leaf can also conduct water. The composition and arrangement of molecules which make up the cuticle transmit and absorb water, presenting an interface between the atmosphere and leaf water stores within the plant (Kerstiens, 1996, see references within). This interface is dynamic and has different transmissivities as the leaf dries when water deficit arises internally (e.g., low xylem water potential) or externally (e.g., high vapor pressure deficit, VPD) (Kerstiens, 1996). A mathematical representation of leaf water potential incorporating the potential for substantial cuticular water loss may be expressed as:

$\psi_{\text {leaf }}=\psi_{\text {soil }}-a \frac{g_{t} * V P D}{K}-\rho g h \quad$,

where $\Psi_{\text {soil }}$ is soil water potential, $\mathrm{K}$ is whole plant hydraulic conductance, $\rho g h$ is gravitational head loss (assumed negligible), $g_{t}$ is total conductance (stomatal conductance $\left(g_{s}\right)+$ cuticular conductance $\left(g_{\text {cuticle }}\right)$ ), and $a$ is a constant. For the sake of simplicity, cuticular conductance and cuticular permeance will be used interchangeably. However, it is important to note the difference in units $\left(\mathrm{m} \mathrm{s}^{-1} \mathrm{vs} . \mathrm{mmol} \mathrm{m}^{-2} \mathrm{~s}^{-2}\right.$, respectively) and that water movement within the cuticle is driven by a concentration gradient whereas water moving from the cuticle to the atmosphere has meteorological dependencies too (e.g., temperature, relative humidity, and as a product VPD; discussed in Kerstiens, 1996).

Cuticular conductance is part of total leaf conductance, but is not typically considered important as stomatal conductance $\left(\mathrm{g}_{\mathrm{s}}\right)$ is dominant most of the time (Duursma et al., 2018; Kerstiens, 1996). As drought intensifies, $g_{s}$ is reduced while $g_{\text {cuticle }}$ may be unchanged, which would cause the ratio of $g_{\text {cuticle: }} g_{t}$ to increase. The magnitude of this error is important when evaluating the isohydricity of a given species based on $\Psi_{\text {leaf }}$ measurements. To illustrate this, we modeled declines in $\Psi_{\text {leaf }}$ under a simulated drought according to Equation 1 allowing $g_{t}$ to be simulated for each instance (i) as follows:

$g_{t}=g_{r e f}(1-0.6 \ln (V P D)) *\left(1-c_{g} \frac{\psi_{s}}{\min \left(\psi_{s}\right)}\right)+g_{\text {cuticle }}$,

where $g_{\text {ref }}$ is a reference conductance rate for well-watered conditions and VPD $=1 \mathrm{kPa}$. The term $(1-0.6 \ln (V P D))$ reduces conductance as a function of increasing VPD, using the formulation proposed

by Oren et al., (1999). The $\left(1-c_{g} \frac{\psi_{S}}{\min \left(\psi_{S}\right)}\right)$ term reduces conductance as a simple linear function of relative soil water potential, where $c_{\mathrm{g}}$ is a sensitivity parameter related to the degree of isohydricity (see MartinezVilalta et al. 2014, Novick et al. 2019). It should be equal to 0 for a perfectly anisohydric species, and larger values represent more isohydric species. To illustrate the importance of $g_{\text {cuticle }}$, drought conditions were modeled and $\Psi_{\text {leaf }}$ was estimated for an anisohydric $\left(\mathrm{c}_{\mathrm{g}}=0.4 ; \mathrm{I}_{40}\right)$ and distinctively more isohydric $\left(\mathrm{c}_{\mathrm{g}}=0.6\right.$; $\left.I_{60}\right)$ species. The subscript here represents the degree of isohydricity. $g_{\text {cuticle }}$ was set to literature reported values converted from cuticular permeance (as per Kerstiens 1996) of Quercus alba (representing I 40 ) and Acer sacharrum (representing $\mathrm{I}_{60}$; Figure 1). As $\mathrm{g}_{\text {cuticle }}$ was set as a constant, it is important to note that our simulation assumes that changes to the ratio of $g_{\text {cuticle }}: g_{t}$ is only determined by changes in $g_{s}$ (Equation 1 ). In reality $\mathrm{g}_{\text {cuticle }}$ (and generally minimum conductance, $\mathrm{g}_{\min }$ ) will change as drought intensifies and temperature increases (see discussions in: Duursma et al., 2018; Kerstiens, 1996, 2006). To evaluate the importance of $\mathrm{g}_{\text {cuticle, }}$, we simulated $\mathrm{g}_{\mathrm{t}}$ for $\mathrm{I}_{60}$ using the reported high cuticular conductance $\left(\mathrm{I}_{60 \mathrm{H}} ; 6.97 \mathrm{mmol}\right.$ $\left.\mathrm{m}^{-2} \mathrm{~s}^{-1}\right)$ for Acer sacharrum, and also simulate $g_{\mathrm{t}}$ using $\mathrm{g}_{\mathrm{s}}$ only $\left(\mathrm{I}_{60} \mathrm{~g}_{\mathrm{s}}\right)$. We used the averaged reported value of $\mathrm{g}_{\text {cuticle }}$ for Quercus alba $\left(\mathrm{I}_{40 \mathrm{~A}} ; 2.56 \mathrm{mmol} \mathrm{m}^{-2} \mathrm{~s}^{-1}\right.$; Figure 1). We calculated a simulated $\sigma$ for each modeled scenario (Figure 1). 
Relative $\Psi_{\text {leaf }}$ reductions in isohydric and anisohydric species can vary substantially simply due to cuticular conductance (Figure 1). Our modeling results indicate that when cuticular conductance is considered, an isohydric species with a permeable cuticle (e.g., $\left.\mathrm{I}_{60 \mathrm{H}}\right)$ could demonstrate $\Psi_{\text {leaf }}$ and $\mathrm{g}_{\mathrm{t}}$ reflective of a distinctly more anisohydric species (e.g., $\mathrm{I}_{40 \mathrm{~A}}$ ) under representative non-drought conditions (Figure 1). Simulated $\sigma$ values were remarkably similar between species with distinct drought responses if cuticular conductance is considered (Figure 1). For example, the simulated $\sigma$ for $\mathrm{I}_{40 \mathrm{~A}}$ and $\mathrm{I}_{60 \mathrm{H}}$ were identical (Figure

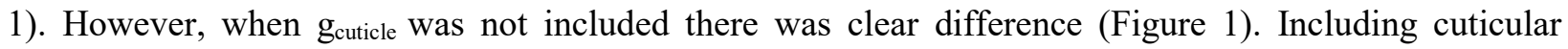
conductance in $\Psi_{\text {leaf }}$ models illustrates how the conventional calculation and interpretation of $\sigma$ can be influenced by traits that do not factor into the definition of $\sigma$ (Figure 1). Specifically, assuming cuticular conductance is negligible while comparing species with different cuticle properties may significantly bias the estimation of $\sigma$.

\section{The consequence of cuticular water loss - empirical evidence}

To assess the influence of cuticular permeance on $\sigma$ using empirical observations, we combined and averaged measurements of cuticular permeance from two sources (Kerstiens, 1996; Schuster, Burghardt, \& Riederer, 2017) and extracted the paired measurements of $\Psi_{\mathrm{PD}}$ and $\Psi_{\mathrm{MD}}$ of any overlapping species in Martinez-Vilalta et al. (2014) (Table 1). It should be noted that some measurements of cuticular conductance are more representative of the sum of $\mathrm{g}_{\text {cuticle }}$ and a non-negligible flux of water from incompletely closed stomata (i.e., gmin, see Kernsteins 1996 and Duursma et al., 2018). A relationship between cuticular conductance and changes in minimum conductance are discussed later in this section.

We focused on angiosperms only due to the differences in stomatal function and xylem structure between angiosperms and gymnosperms. For example, guard cell sensitivity to abscisic acid (ABA) over drought conditions is different between the two clades (discussed in Brodribb \& McAdam, 2017). In response to rises in VPD, angiosperms upregulate ABA synthesis within minutes causing fast stomatal closure, likely due to high speed gene expression at a critical step in ABA synthesis (McAdam, Sussmilch, $\&$ Brodribb, 2016). Within the gymnosperm clade there is not a uniform control of stomatal conductance. Instead, there are reports of more passive regulation of $g_{s}$ with no significant increase in ABA (McAdam \& Brodribb, 2015), other instances where sufficient ABA concentrations to induce stomatal closure took more than six hours to reach (McAdam \& Brodribb, 2014). Such differences would complicate our analysis which uses observations from multiple time scales (days to months) and make interpreting results subject to error.

Measurements of leaf water potential conducted on seedlings, branches, exclusively riparian species with constant groundwater access (e.g., some Populus species) and under potentially biasing treatments (e.g., greenhouse, increased salinity) were excluded to assess the relationship between permeance and $\sigma$. Additionally, if $\Psi_{\mathrm{PD}}$ and $\Psi_{\mathrm{MD}}$ were present, but could not be obviously extracted as a pair, these were also excluded. Ranges of $\Psi_{\text {leaf }}$ for the species presented here may not reflect exactly what was used in the analysis by Martinez-Vilalta et al. (2014). Therefore, we made a modified estimate of the degree of isohydricity with the same method in Martinez-Vilalta et al. (2014) using our extracted $\Psi_{\text {leaf }}$ data from articles which fit our criteria (hereafter $\sigma_{\text {calc }}$ ). For discussion purposes $\sigma_{\text {calc }}$ was used interchangeably with the reported $\sigma$ values in Martinez-Vilalta et al. (2014) as their relationships with cuticular permeance were not different (Figure 2).

In addition to the calculations of $\sigma$, we introduced a new parameter, $\Gamma$, defined as the correlation (r) between $\Psi_{\mathrm{PD}}-\Psi_{\mathrm{MD}}$ and $\Psi_{\mathrm{PD}}$, when $\Psi_{\mathrm{PD}}>\Psi_{\mathrm{MD}}$, similar in principle to an analysis by Meinzer et al. (2016) (Figure 2). The $\Gamma$ value enhances understanding that can be gained using $\sigma$ in a few important ways. First, the calculated $\Gamma$ values for each species are confined to a range (-1 to 1$)$ whereas $\sigma$ is unbounded. Second, $\Gamma$ provides information not only about the direction of the relationship between pre-dawn and mid-day leaf 
water potential, but also provides information about the covariability between the two. This is important, because $\sigma$, as traditionally defined (e.g., Martinez-Vilalta et al. 2014), does not directly accommodate the influence of vapor pressure deficit, among other factors, on the dynamics of $\Psi_{\mathrm{MD}}$ (Novick, Konings, \& Gentine, 2019). Assuming all water flux from the leaf is through the stomata, and that $\sigma$ is an appropriate indicator of isohydricity (e.g., influence of VPD and other variables is small), then more negative $\Gamma$ values should represent a more 'wasteful' physiotype within the traditional framework, meaning that as $\Psi_{\mathrm{PD}}$ declines $\Psi_{\mathrm{MD}}$ will also decline, reflecting an anisohydric water use strategy and/or higher cuticular permeance. Positive $\Gamma$ values represent a 'conservative' physiotype where $\Psi_{\text {MD }}$ will be more stationary as soil drying progresses, likely related to species with an isohydric water use strategy and/or lower permeance. In both of these examples, $\sigma$ and $\Gamma$ should be relatively well coupled across species and sites. However, if VPD or other factors substantially affect the relationship between $\Psi_{\mathrm{PD}}$ and $\Psi_{\mathrm{MD}}$, then $\Gamma$ and $\sigma$ will be less coupled from one species to the next. Thus, considering both metrics, if they lead to similar conclusions, can increase confidence that results are not driven by spurious excursions in $\Psi_{\mathrm{MD}}$, for example due to passing fronts that may affect VPD more than $\Psi_{\text {PD. }}$. It should be noted that such representation of isohydricity may only be relevant for species at the extremes of the isohydric continuum, thus $\Gamma$ should only be used as a diagnostic parameter. Likewise, both $\Gamma$ and $\sigma$ could also be sensitive to non-cuticular impacts (e.g., cavitation).

Calculated $\Gamma$ and the reported $\sigma$ values from Martinez-Vilalta et al. (2014) were compared against the extracted values of cuticular permeance from Kersteins (1996) and Schuster et al. (2017) using simple linear regression. Cuticular permeance and $\Gamma$ had a predictable relationship (Figure 3). Species with the lowest permeance of the dataset also had the highest $\Gamma$, meaning that at low $\Psi_{\mathrm{PD}}, \Psi_{\mathrm{MD}}$ is not likely to change (Figure 2, Table 1). Conversely, the species with the highest cuticular permeance had the lowest $\Gamma$, indicating continued leaf dehydration as $\Psi_{\mathrm{PD}}$ decreases (Figure $3, \mathrm{R}^{2}=0.86, \mathrm{p}=0.02$ ). $\sigma$ values for all the study species were ranked the same way and were well described by the extracted cuticular permeance values, though Fagus sylvatica deviated slightly from the overall line trend causing the relationship with $\sigma_{\text {calc }}$ to be marginally significant (Table 1 , Figure $3, R^{2}=0.86$ and $0.71, p=0.02,0.07$ for $\sigma$ and $\sigma_{\text {calc, }}$ respectively). The relationship between cuticular permeance and $\sigma$ observed in this analysis suggests there may be an inherent classification bias for species at the extremes of the permeance spectrum (Figure 3). The values of $\sigma$ and $\Gamma$ seem to be well characterized, if not constrained, by the cuticular permeance of the plant and thus may not independently provide an ecologically relevant mechanism as to how the plant survives drought or how such a response will affect carbon and water cycling (Figure 3).

Concurrent measurements of cuticular conductance and leaf water potential under natural or controlled conditions were not available in literature. The natural variability of cuticular permeance of an average cuticle is not known for any of the species included in this analysis, most of which are important hardwood trees common to the northeastern United States. All of these limit the robustness of our conclusions about the importance of cuticular permeance on plant water use. However, besides our own analyses, multiple observations implicate cuticular permeance as an important and dynamic component of leaf hydrology. For example, a study by Boyer, Wong, \& Farquhar, 1997 shows that leaf age can cause a substantial increase in permeance, increasing from $10 \%$ of $g_{s}$ to nearly $30 \%$ of $g_{s}$ in Vitis vinifera $L$. (grapes), thus imposing leaf level drought stress in older fraction of the canopy earlier than the younger fraction. There is also evidence that a drying cuticle can have enough 'mechanical advantage' over nearby stomata to pull them open, increasing $g_{\min }$ (Buckley 2005). As discussed in detail by Kersteins (1996) and Duursma et al. (2018), some reported measurements of $g_{\text {cuticle }}$ may actually be more representative of $g_{\min }$, which is important since the dehydration of the cuticle could lead to higher $\mathrm{g}_{\text {min. }}$. Growth conditions associated with dry leaves (e.g., high temperature) can also lead to reduced $g_{\min }$ as shown by Duursma et al., (2018) in Eucalyptus parraattensis, however, the impact of higher temperature on $g_{\text {min }}$ or $g_{\text {cuticle }}$ across 
species is largely unassessed, preventing any complete understanding of plant transpiration response under future climates.

\section{Conclusions and future directions}

Based on modeling exercises and empirical analysis, our results indicate that cuticular properties are important in regulating plant water use and should be considered for a more holistic evaluation of the links between gas exchange and leaf water potential during water stress going forward. To aid in such efforts, $\Gamma$ could serve as a good quality control parameter prior to using $\sigma$ as a classifier of isohydricity. For example, if the $\Gamma$ value of two species is similar it may be appropriate to classify them using $\sigma$ values. However, if the species with a larger $\sigma$ value also has a strong negative $\Gamma$ value (e.g., Acer sacharrum), $\Psi_{\text {leaf }}$ measurements alone should be used with caution. In such circumstances, it would be best to determine the relative isohydricity by comparing stomatal conductance and $\Psi_{\text {leaf }}$ in a variety of environmental conditions, not relying on the relationship between $\Psi_{\mathrm{PD}}$ and $\Psi_{\mathrm{MD}}$ alone.

Though this study was written to include discussions of the isohydric framework, it is important to emphasize that there appears to be a close relationship between $\Psi_{\text {leaf }}$ declines, permeance, and plant water stress, regardless the actual utility of plant isohydricity classifications. It is expected that droughts will occur under warmer conditions and that VPD in many plant dominated ecosystems will likely increase (Novick et al., 2016). Additionally, land-atmosphere feedbacks can prolong arid atmospheric conditions (Zhou et al., 2019), causing variations in $g_{\text {cuticle }}$ and $g_{\min }$, meaning that our findings and modeled examples might underestimate the influence of cuticular conductance in future climate scenarios as our analysis keeps $g_{\text {cuticle }}$ constant. Plant acclimatization to warmer conditions also will likely impact $g_{\text {cuticle }}$ and $g_{\min }$ (Duursma et al., 2018) - another instance where water and carbon cycling will be impacted in the future but empirical data is lacking at present. Based on our current analyses and literature information, the seemingly small effect of cuticular conductance could play a large role in both how vegetation responds to drought and in forest management decisions, which will rely on accurate representations and predictions of forest response to drought. To meet that need, it will be important for researchers to begin incorporating measurements and estimations of cuticular conductance in their experiments.

\section{Acknowledgments}

We acknowledge support from Division of Earth Sciences of National Science Foundation (NSF EAR1554894) and from the Agriculture and Food Research Initiative program (2017-67013-26191) of the USDA National Institute of Food and Agriculture. We thank the comments from two anonymous reviewers, which significantly improved the quality of the manuscript.

\section{Authors' Contributions}

ML and LW conceptualized the main research questions. ML collected data and performed the data analyses. ML and LW wrote the first draft. KAN contributed modeling analyses and revised manuscript. 


\section{References}

Aranda, I., Gil, L., \& Pardos, J. A. (2005). Seasonal Changes in Apparent Hydraulic Conductance and Their Implications for Water Use of European Beech (Fagus sylvatica L.) and Sessile Oak [Quercus petraea (Matt.) Liebl] in South Europe. Plant Ecology, 179(2), 155-167. https://doi.org/10.1007/s

Aranda, Ismael, Gil, L., \& Pardos, J. A. (2000). Water relations and gas exchange in Fagus sylvatica L. and Quercus petraea (Mattuschka) Liebl. in a mixed stand at their southern limit of distribution in Europe. Trees - Structure and Function, 14(6), 344-352. https://doi.org/10.1007/s004680050229

Boyer, J. S., Wong, C. S., \& Farquhar, G. D. (1997). CO2 and water vapor exchange across leaf cuticle (epidermis) at various water potentials. Plant Physiology, 114(1), 185-191. https://doi.org/10.1104/pp.114.1.185

Breda, N., Cochard, H., Dreyer, E., \& Granier, A. (1993). Water transfer in a mature oak stand (Quercus petrea): seasonal evolution and effects of a severe drought. Canadian Journal of Forest Research, 23, 1136-1143. https://doi.org/https://doi.org/10.1139/x93-144

Brodribb, T. J., \& McAdam, S. A. M. (2017). Evolution of the Stomatal Regulation of Plant Water Content. Plant Physiology, 174(2), 639-649. https://doi.org/10.1104/pp.17.00078

Buckley, T. N. (2005). The control of stomata by water balance. New Phytologist, 168, 275-292. https://doi.org/10.1111/j.1469-8137.2005.01543.x

Cubera, E., \& Moreno, G. (2007a). Effect of land-use on soil water dynamic in dehesas of Cental-Western Spain. Catena, 71(2), 298-308. https://doi.org/doi:10.1016/j.catena.2007.01.005

Cubera, E., \& Moreno, G. (2007b). Effect of single Quercus ilex trees upon spatial and seasonal changes in soil water content in dehesas of central western Spain. Annals of Forest Science, 64(3), 355-364. https://doi.org/DOI 10.1051/forest:2007012

Duursma, R. A., Blackman, C. J., Lopéz, R., Martin-StPaul, N. K., Cochard, H., \& Medlyn, B. E. (2018). On the minimum leaf conductance: its role in models of plant water use, and ecological and environmental controls. New Phytologist, 221(2), 693-705. https://doi.org/10.1111/nph.15395

Hochberg, U., Rockwell, F. E., Holbrook, N. M., \& Cochard, H. (2018). Iso / Anisohydry : A plant environment interaction rather than a simple hydraulic trait. Trends in Plant Science, 23(2), 112120. https://doi.org/10.1016/j.tplants.2017.11.002

Jasechko, S., Sharp, Z. D., Gibson, J. J., Birks, S. J., Yi, Y., \& Fawcett, P. J. (2013). Terrestrial water fluxes dominated by transpiration. Nature, 496(7445), 347-350. https://doi.org/10.1038/nature11983

Kannenberg, S. A., Novick, K. A., \& Phillips, R. P. (2019). Anisohydric behavior linked to persistent hydraulic damage and delayed drought recovery across seven North American tree species. New Phytologist, 222(4), 1862-1872. https://doi.org/10.1111/nph.15699

Kerstiens, G. (1996). Cuticular water permeability and its physiological significance. Journal of Experimental Botany, 47(305), 1813-1832. https://doi.org/10.1093/jxb/47.12.1813

Kerstiens, G. (2006). Water transport in plant cuticles : an update. Journal of Expemental Botany, 57(11), 2493-2499. https://doi.org/10.1093/jxb/er1017

Klein, T. (2014). The variability of stomatal sensitivity to leaf water potential across tree species indicates a continuum between isohydric and anisohydric behaviours. Functional Ecology, 28(6), 1313-1320. https://doi.org/10.1111/1365-2435.12289

Lanning, M., Wang, L., Scanlon, T. M., Vadeboncoeur, M. A., Adams, M. B., Epstein, H. E., \& 
Druckenbrod, D. (2019). Intensified vegetation water use under acid deposition. Science Advances, 5(7), eaav5168. https://doi.org/10.1126/sciadv.aav5168

Loewenstein, N. J., \& Pallardy, S. G. (1998). Drought tolerance, xylem sap abscisic acid and stomatal conductance during soil drying: a comparison of canopy trees of three temperate deciduous angiosperms. Tree Physiology, 18(7), 431-439.

Martínez-Vilalta, J., \& Garcia-Forner, N. (2017). Water potential regulation, stomatal behaviour and hydraulic transport under drought: deconstructing the iso/anisohydric concept. Plant Cell and Environment, 40(6), 962-976. https://doi.org/10.1111/pce.12846

Martínez-Vilalta, J., Mangirón, M., Ogaya, R., Sauret, M., Serrano, L., Peñuelas, J., \& Piñol, J. (2003). Sap flow of three co-occurring Mediterranean woody species under varying atmospheric and soil water conditions. Tree Physiology, 23(11), 747-758. https://doi.org/10.1093/treephys/23.11.747

Martinez-Vilalta, J., Poyatos, R., Aguade, D., Retana, J., \& Mencuccini, M. (2014). A new look at water transport regulation in plants. New Phytologist, 204(1), 105-115. https://doi.org/10.1111/nph.12912

Martínez-Vilalta, J., Prat, E., Oliveras, I., \& Piñol, J. (2002). Xylem Hydraulic Properties of Roots and Stems of Nine Mediterranean Woody Species. Oecologia, 133(1), 19-29. https://doi.org/10.1007/s00442-002-1009-2

Matheny, A. M., Fiorella, R. P., Bohrer, G., Poulsen, C. J., Morin, T. H., Wunderlich, A., ... Curtis, P. S. (2016). Contrasting strategies of hydraulic control in two codominant temperate tree species. Ecohydrology, 10(3), e1815. https://doi.org/10.1002/eco.1815

McAdam, S. A. M., \& Brodribb, T. J. (2014). Separating active and passive influences on stomatal control of transpiration. Plant Physiology, 164(4), 1578-1586. https://doi.org/10.1104/pp.113.231944

McAdam, S. A. M., \& Brodribb, T. J. (2015). The Evolution of Mechanisms Driving the Stomatal Response to Vapor Pressure Deficit. Plant Physiology, 167(3), 833-843. https://doi.org/10.1104/pp.114.252940

McAdam, S. A. M., Sussmilch, F. C., \& Brodribb, T. J. (2016). Stomatal responses to vapour pressure deficit are regulated by high speed gene expression in angiosperms. Plant Cell and Environment, 39(3), 485-491. https://doi.org/10.1111/pce.12633

Meinzer, F. C., Woodruff, D. R., Marias, D. E., Smith, D. D., McCulloh, K. A., Howard, A. R., \& Magedman, A. L. (2016). Mapping 'hydroscapes' along the iso- to anisohydric continuum of stomatal regulation of plant water status. Ecology Letters, 19(11), 1343-1352. https://doi.org/10.1111/ele.12670

Novick, K. A., Ficklin, D. L., Stoy, P. C., Williams, C. A., Bohrer, G., Oishi, A. C., .. Phillips, R. P. (2016). The increasing importance of atmospheric demand for ecosystem water and carbon fluxes. Nature Climate Change, 6, 1023-1027. https://doi.org/doi:10.1038/nclimate3114

Novick, K. A., Konings, A. G., \& Gentine, P. (2019). Beyond soil water potential: An expanded view on isohydricity including land-atmosphere interactions and phenology. Plant Cell and Environment, 42(6), 1802-1815. https://doi.org/10.1111/pce.13517

Oren, R., Sperry, J., Katul, G., Pataki, D., Ewers, B., Phillips, N., \& Schäfer, K. (1999). Survey and synthesis of intra-and interspecific variation in stomatal sensitivity to vapour pressure deficit. Plant, Cell \& Environment, 22(12), 1515-1526. https://doi.org/10.1046/j.1365-3040.1999.00513.x

Roman, D. T., Novick, K. A., Brzostek, E. R., Dragoni, D., Rahman, F., \& Phillips, R. P. (2015). The role 
of isohydric and anisohydric species in determining ecosystem-scale response to severe drought. Oecologia, 179(3), 641-654. https://doi.org/10.1007/s00442-015-3380-9

Schlesinger, W. H., \& Jasechko, S. (2014). Transpiration in the global water cycle. Agricultural and Forest Meteorology, 189-190(0), 115-117.

https://doi.org/http://dx.doi.org/10.1016/j.agrformet.2014.01.011

Schuster, A. C., Burghardt, M., \& Riederer, M. (2017). The ecophysiology of leaf cuticular transpiration: are cuticular water permeabilities adapted to ecological conditions? Journal of Experimental Botany, 68(19), 5271-5279. https://doi.org/10.1093/jxb/erx321

Serrano, L., \& Peñuelas, J. (2005). Contribution of physiological and morphological adjustments to drought resistance in two Mediterranean tree species. Biologia Plantarum, 49(4), 551-559. https://doi.org/10.1007/s10535-005-0049-y

Tardieu, F., Lafarge, T., \& Simonneau, T. (1996). Stomatal control by fed or endogenous xylem ABA in sunflower: Interpretation of correlations between leaf water potential and stomatal conductance in anisohydric species. Plant, Cell and Environment, 19(Tardieu 1993), 75-84.

https://doi.org/10.1111/j.1365-3040.1996.tb00228.x

Thomsen, J. E., Bohrer, G., Matheny, A. M., Ivanov, V. Y., He, L., Renninger, H. J., \& Schäfer, K. V. R. (2013). Contrasting hydraulic strategies during dry soil conditions in Quercus rubra and Acer rubrum in a sandy site in Michigan. Forests, 4(4), 1106-1120. https://doi.org/10.3390/f4041106

Wang, L., Good, S. P., \& Caylor, K. K. (2014). Global synthesis of vegetation control on evapotranspiration partitioning. Geophysical Research Letters, 41, 1-5. https://doi.org/10.1002/2014GL061439

Yi, K., Dragoni, D., Phillips, R. P., Roman, D. T., \& Novick, K. A. (2017). Dynamics of stem water uptake among isohydric and anisohydric species experiencing a severe drought. Tree Physiology, 37(10), 1379-1392. https://doi.org/10.1093/treephys/tpw126

Zhou, S., Williams, A. P., Berg, A. M., Cook, B. I., Zhang, Y., Hagemann, S., ... Gentine, P. (2019). Land-atmosphere feedbacks exacerbate concurrent soil drought and atmospheric aridity. PNAS, 116(38), 18848-18853. 
Table 1 Complied species level values of cuticular permeance, $\sigma$ (slope of regression of $\Psi_{\mathrm{MD}} \mathrm{VS} \Psi_{\mathrm{PD}}, \sigma_{\text {calc }}$ (same as $\sigma$ but from mature trees in a natural setting), and $\Gamma$ (the correlation of the regression between $\Psi_{\mathrm{PD}}$ - $\Psi_{\mathrm{MD}}$ and $\Psi_{\mathrm{PD}}$ ) as well as the source of the leaf water potential ( $\left.\Psi_{\text {leaf }}\right)$ data. Values from non-significant regression marked with 'NS'.

\begin{tabular}{|c|c|c|c|c|c|c|c|}
\hline Species & $\begin{array}{l}\text { Letter } \\
\text { Code }\end{array}$ & $\begin{array}{c}\text { Cuticular } \\
\text { Permaince } \\
\left(\mathrm{ms}^{-1} \times 10^{-5}\right) \\
\end{array}$ & $\sigma^{* * *}$ & $\sigma_{\text {calc }}$ & $\Gamma$ & $\begin{array}{l}\text { Sampling } \\
\text { Resolution }\end{array}$ & $\Psi_{\text {leaf }}$ Data Sources \\
\hline Acer saccharum & AS & $8.13^{*, * *}$ & 1.127 & 1.46 & -0.58 & $\begin{array}{l}\text { multiple } \\
\text { days }\end{array}$ & Loewenstein and Pallardy 1998 \\
\hline Fagus sylvatica & FS & $5.28^{*, * *}$ & 0.681 & 0.39 & 0.63 & $\begin{array}{l}\text { one day, } \\
\text { multiple } \\
\text { days }\end{array}$ & $\begin{array}{l}\text { Ismael Aranda, Gil, and Pardos } \\
\text { 2000; I. Aranda, Gil, and Pardos } \\
2005\end{array}$ \\
\hline Quercus alba & QA & $7.4^{*}$ & 0.918 & 1.28 & $-0.32^{\mathrm{NS}}$ & $\begin{array}{l}\text { multiple } \\
\text { days }\end{array}$ & Loewenstein and Pallardy 1998 \\
\hline Quercus ilex & QI & $3.6^{*}$ & 0.652 & 0.58 & 0.71 & various & $\begin{array}{l}\text { Martínez-Vilalta et al. 2002, } \\
\text { 2003; Serrano and Peñuelas 2005; } \\
\text { Cubera and Moreno 2007b, 2007a }\end{array}$ \\
\hline Quercus petra & QP & $5.55^{* *}$ & 0.829 & 1.09 & $-0.03^{\mathrm{NS}}$ & various & $\begin{array}{l}\text { Ismael Aranda, Gil, and Pardos } \\
\text { 2000; I. Aranda, Gil, and Pardos } \\
\text { 2005; Breda et al. } 1993\end{array}$ \\
\hline
\end{tabular}

* Kerstiens 1996

** Schuster, Burghardt, and Riederer 2017

****Martinez-Vilalta et al. 2014 


\section{Figure legends}

Figure 1 Modeled leaf water potential (top) and total leaf conductance ( $\mathrm{g}_{\mathrm{t}}$, bottom) for simulated $\mathrm{I}_{60}$ and $\mathrm{I}_{40}$ plants according to equations 1 and 2 . The subscripts ' 60 ' and ' 40 ' refer to the degree of isohydricity the modeled plant represents as described in section 1 . The simulations were made using the $\mathrm{g}_{\mathrm{s}}$ only $\left(\mathrm{I}_{60} \mathrm{~g}_{\mathrm{s}}\right)$ and reported high $\left(\mathrm{I}_{60 \mathrm{H}} ; 6.97 \mathrm{mmol} \mathrm{m}^{-2} \mathrm{~s}^{-1}\right)$ estimations of cuticular conductance for Acer sacharrum and the reported estimation of cuticular conductance for Quercus alba $\left(\mathrm{I}_{40 \mathrm{~A}} ; 2.56 \mathrm{mmol} \mathrm{m}^{-2} \mathrm{~s}^{-1}\right)$. Simulated $\sigma$ values are the slopes of the line equation reported in the top figure.

Figure 2 The correlations between measured pre-dawn leaf water potential $\left(\Psi_{\mathrm{PD}}\right)$ and midday leaf water potential $\left(\Psi_{\mathrm{MD}}\right)(\sigma)$ as well as between $\Psi_{\mathrm{PD}}-\Psi_{\mathrm{MD}}$ and $\Psi_{\mathrm{PD}}(\Gamma)$ for different species. The filled circles correspond to the data used to calculate $\sigma$ and the open circles correspond to the data used to calculate $\Gamma$. Regression lines are shown to indicate direction and please note the difference in $\mathrm{x}$-axis scales.

Figure 3 Observed relationships between $\sigma$ (solid line), $\sigma_{\text {calc }}$ (dashed line), $\Gamma$ (dotted line), and cuticular

permeance. The two-letter codes above correspond to the following individual species and are listed in Table 1: QI = Quercus ilex; FS = Fagus sylvatica; $\mathrm{QP}=$ Quercus petrea; $\mathrm{QA}=$ Quercus alba; $\mathrm{AS}=$ Acer saccharum. 

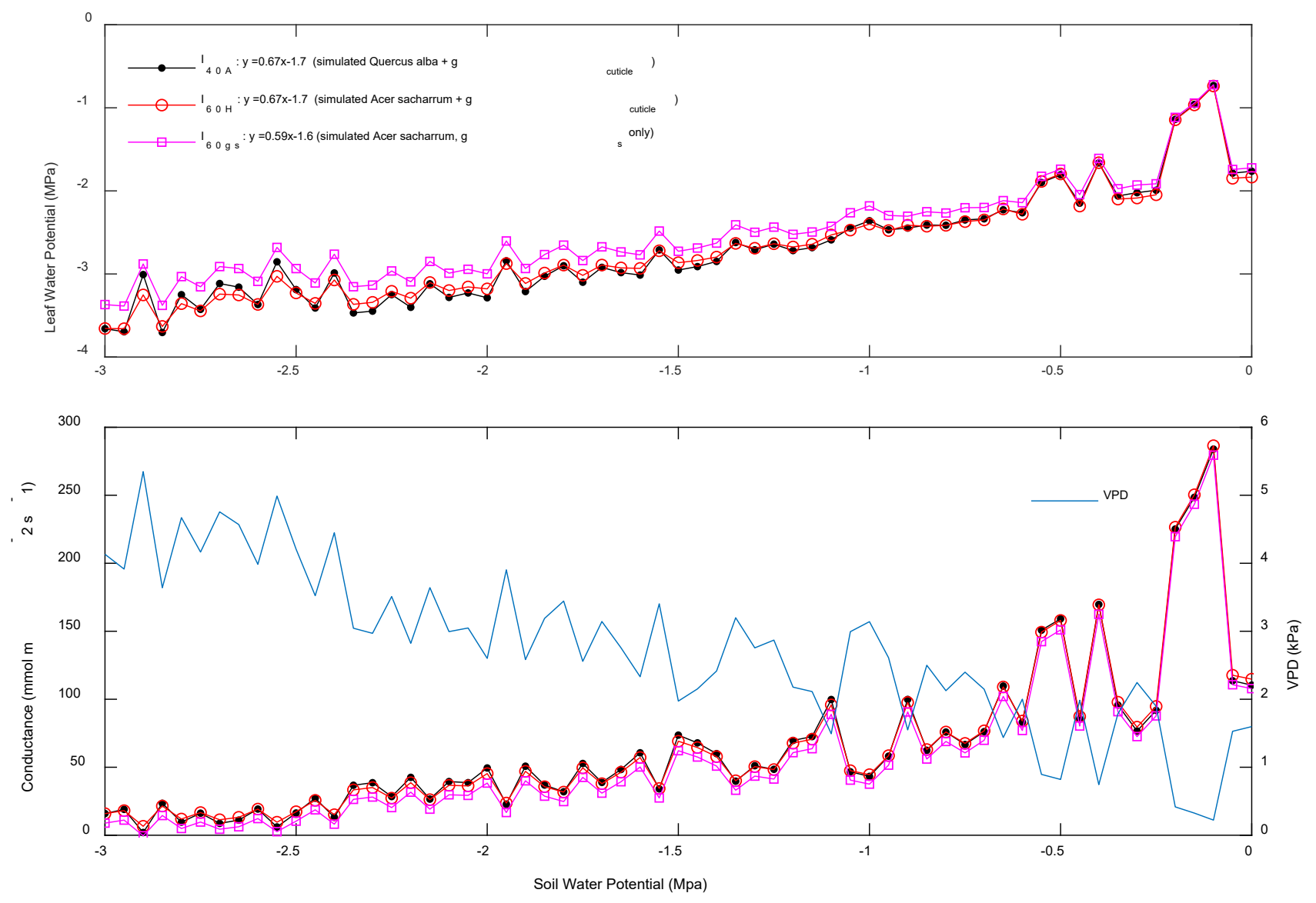

Figure 1 


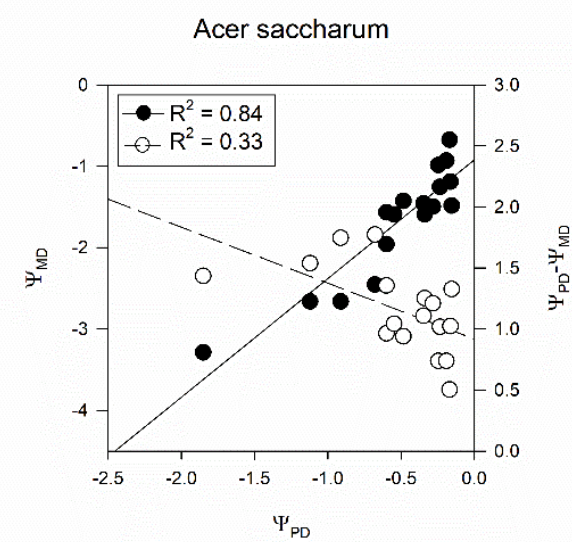

Fagus sylvatica

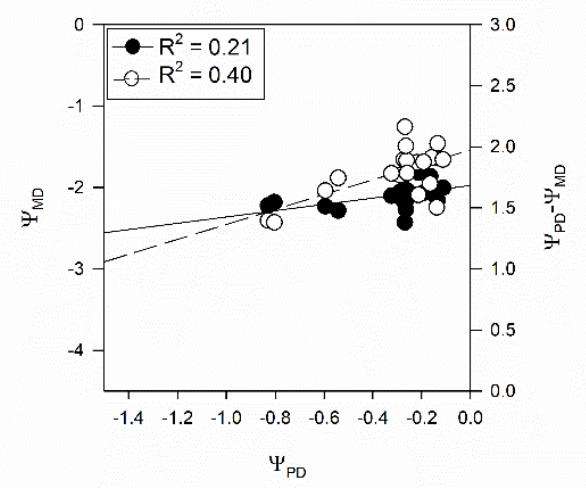

Quercus petrea

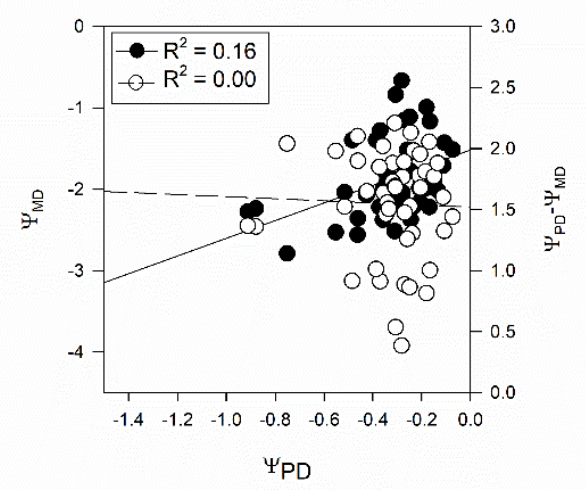

Quercus ilex

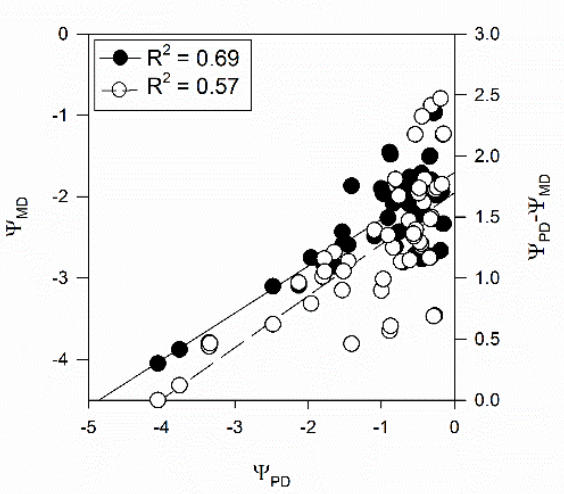

Quercus alba

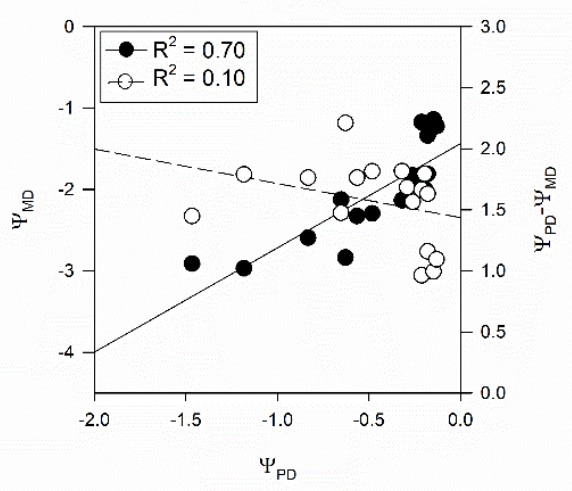

Figure 2 


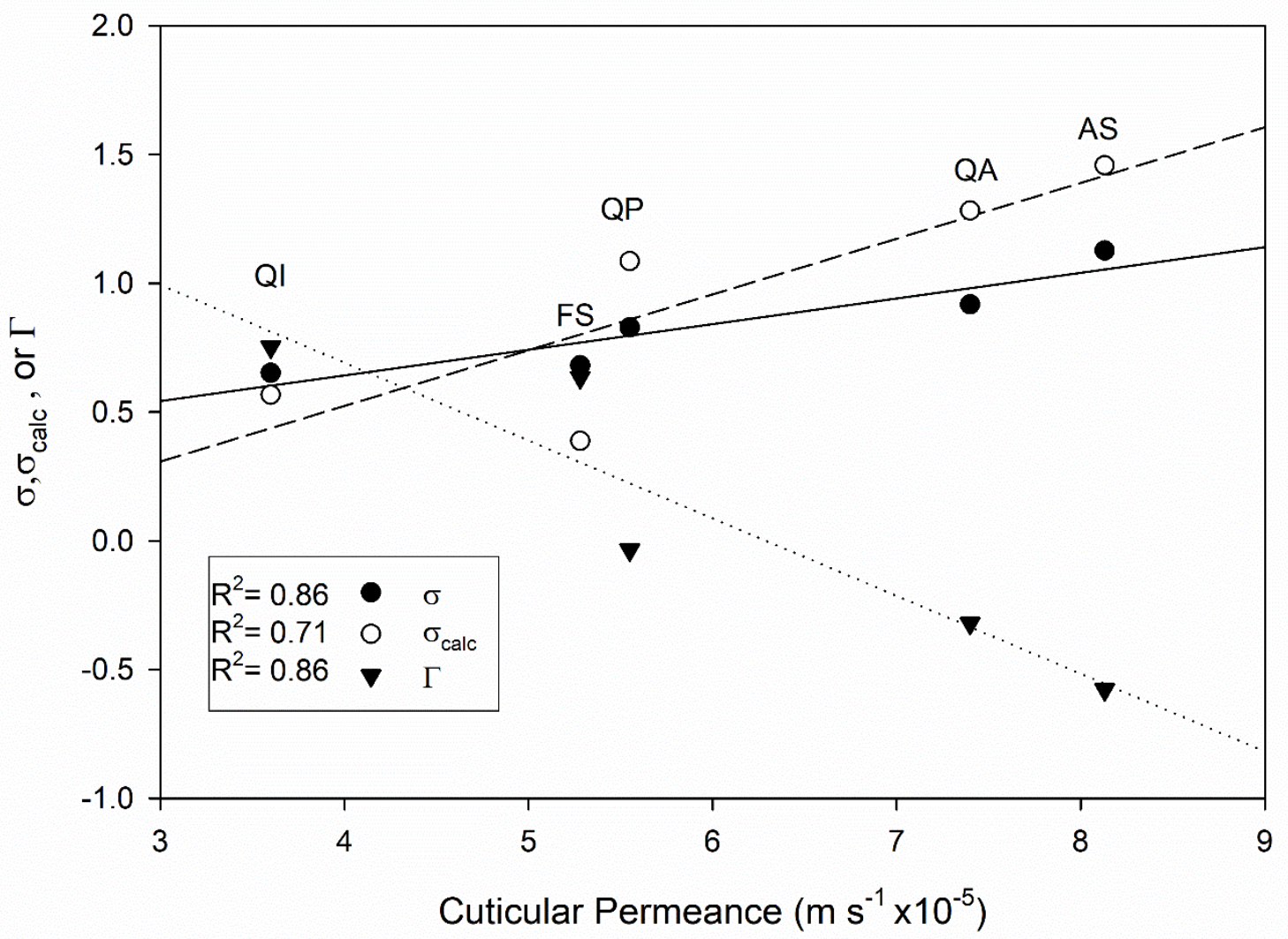

Figure 3 